\title{
Morphological transition of Helicobacter pylori adapted to water
}

\author{
Ricardo M Fernandes ${ }^{1}$, Hélder Silva' ${ }^{1}$, Ricardo Oliveira' ${ }^{1}$, Carina Almeida*1,2,3, \\ Nuno F Azevedo ${ }^{2} \&$ Maria J Vieira'
}

\begin{abstract}
Aim: This study aims to investigate the morphological transition of Helicobacter pylori during adaptation to water. Materials \& methods: Different strains were adapted to water. Changes regarding cultivability and cellular morphology were recorded. Expression of 11 genes involved in $H$. pylori morphological changes was evaluated by real-time PCR. Results: H. pylori presented increased cultivability in water after adaptation. The permanent loss of the spiral shape was observed, but no transition into coccoid form has occurred. Expression levels of genes involved in peptidoglycan assembly of H. pylori 26695 have shown significant changes between adapted and nonadapted strains. Conclusion: Adaption to water favors the culturable phenotype and the morphological transition to the rod shape, into a process that implicates the peptidoglycan turnover.
\end{abstract}

First draft submitted: 30 August 2016; Accepted for publication: 15 November 2016; Published online: 7 September 2017

Helicobacter pylori, a spiral-shaped pathogenic bacterium found on the human gastric mucosa, was first isolated by Warren and Marshall in 1982 [1]. H. pylori is one of the most prevalent pathogens in humans, especially in developing countries, where the incidence of the infection can be up to $90 \%$ of the population [2]. H. pylori infection can lead to the development of peptic and duodenal ulcer disease and gastric mucosa associated lymphoid tissue lymphoma, even though most individuals infected by this pathogen are asymptomatic [3]. The epidemiology of $H$. pylori infection is characterized by marked differences between developing and developed countries, notably among children $[2,4-5]$. At present, the route of transmission is perhaps one of the most controversial areas in $H$. pylori research. Several epidemiological studies have investigated ingestion of water as a risk factor for $H$. pylori infection [6]. These studies have shown an association between water sources and the prevalence of $H$. pylori infection and, as such, have provided evidence for waterborne transmission of $H$. pylori [2,4-5,7]. Additionally, molecular methods (such as FISH, PCR and antibody assays) and culture methods were able to detect the presence of planktonic bacteria and biofilms in water from wells, rivers and water distribution networks [5,8-11].

Studies in controlled laboratory settings have also revealed that, when introduced into an aqueous environment, $H$. pylori can survive for extended periods of time, and the length of that time is affected by a number of specific conditions of the aqueous environment [6,12-13]. H. pylori

'Centre of Biological Engineering, Universidade do Minho, Campus de Gualtar 4710-057, Braga, Portugal

2LEPABE, Department of Chemical Engineering, Faculty of Engineering, University of Porto, Rua Dr Roberto Frias, 4200-465 Porto,

Portugal

${ }^{3}$ INIAV, IP - National Institute for Agrarian \& Veterinary Research, Rua dos Lagidos, Lugar da Madalena, 4485-655 Vairão, Vila do Conde,

Portugal

*Author for correspondence: Tel.: +351 252 660600; Fax: +252 660695; carina.almeida@iniav.pt

\section{KEYWORDS}

- adaptation $\bullet$ Helicobacter pylori • morphological transition • peptidoglycan

- water 
cultivability in water usually ends after a short time when compared with known waterborne pathogens [14]. In fact, several studies report cultivability times of $<10 \mathrm{~h}$ for $H$. pylori $[12,15]$ at temperatures over $20^{\circ} \mathrm{C}$ which compares to cultivability times of more than 40 days for Escherichia coli and Salmonella Typhimurium at the same temperature.

It is still unclear if Helicobacter spp. are able to adapt and persist into water reservoirs. However, many living organisms are equipped with mechanisms that allow extended survival under adverse environments and for a number of them, this response involves, besides metabolic adaptations, changes in cell morphology [16,17]. This is the case of $H$. pylori, which is known to mainly maintain a spiral shape within the human host, but is able to convert into a coccoid shape (reported as a viable but nonculturable state) when exposed to detrimental environmental circumstances [18,19]. Several studies have shown that $H$. pylori morphology is closely associated to the peptidoglycan composition [20-25]. The peptidoglycan is a highly complex macromolecule composed by $\mathrm{N}$-acetylD-glucosamine- $(\beta 1,4)-\mathrm{N}$-acetylmuramic acid pentapeptide. Its complexity is the result of the action of different enzymes, including glycosyltranferases, transpeptidases, carboxypeptidases, endopeptidases and hydrolases [20].

The main goal of this work is to understand the adaptation mechanisms of $H$. pylori to water and thus try to establish the role that water plays in its transmission. For this, different strains of $H$. pylori were exposed/adapted to water in order to evaluate its effect on cultivability, cellular morphology and genes expression associated with the morphological transition.

\section{Materials \& methods}

\section{- Culture maintenance}

Strains were maintained as previously described [13]. All Helicobacter strains were maintained on Columbia agar (Liofilchem, Italy) supplemented with $5 \%(\mathrm{vol} / \mathrm{vol})$ defibrinated horse blood (Probiológica, Portugal). Plates were incubated at $37^{\circ} \mathrm{C}$ in a $\mathrm{CO}_{2}$ incubator (HERAcell 150; Thermo Electron Corporation, MA, USA) set to $10 \% \mathrm{CO}_{2}$ and $5 \% \mathrm{O}_{2}$, and bacteria were streaked onto fresh plates every 2 or 3 days [13]. Strains used were the following: H. pylori 26695; H. pylori NCTC 11367 ; H. pylori 167; Helicobacter pametensis; Helicobacter bilis; Helicobacter pullorum; Helicobacter canis; Helicobacter mustelae 2H1; Helicobacter muridarum; Helicobacter cinaedi 33221 - 1.2; Helicobacter canadensis; and Helicobacter salomonis. Helicobacter strains were kindly provided by Maria Lurdes Monteiro, Jay Solnick and Francis Mégraud. More details on the strains can be found in the Supplementary Table 1.

\section{- Cellular suspension preparation}

Bacterial suspensions were prepared as previously described [13]. For all experiments, cells from 2-day-old cultures were harvested from Columbia blood agar (CBA, Liofilchem, Italy), suspended in approximately $20 \mathrm{ml}$ of autoclaved distilled water $(\mathrm{pH} \mathrm{7,}$, resistivity $\sim 18 \mathrm{M} \Omega \mathrm{cm}$ ) and subjected to a vortex for $1 \mathrm{~min}$ for homogenization. The cell density was assessed by determining the optical density (OD) at $640 \mathrm{~nm}$, and the necessary volume of this initial inoculum was then used in order to obtain a final density of approximately $10^{8}$ total cells $/ \mathrm{ml}$ of sterile water. The relationship between OD and total cell counts was previously established by performing microscopic cell counts and OD readings at several cell dilutions. For this, $200 \mu \mathrm{l}$ of the cell suspensions with different OD were filtered through a $25 \mathrm{~mm}$ black nuclepore polycarbonate membrane with a pore size of $0.2 \mu \mathrm{m}$ (Whatman, Kent, UK). The polycarbonate membrane was stained with $40 \mu \mathrm{l}$ of 4'-6-Diamidino-2phenylindole $(100 \mu \mathrm{g} / \mathrm{ml})$ for $10 \mathrm{~min}$ in the dark. Then the membrane was washed with water and placed in a microscope slide. Samples were allowed to dry, mounted with one drop of nonfluorescent immersion oil (Merck) and covered with coverslips. Cells were visualized under an epifluorescence microscope (BX51; Olympus, Lisbon, Portugal) equipped with a CCD camera (DP71; Olympus) and filters capable of detecting 4'-6-Diamidino-2-phenylindole (BP 365-370, FT 400, LP 421). A total of 15 fields with an area of $0.0144 \mathrm{~mm}^{2}$ were subjected to counting, and the average result was used to calculate the total number of cells per $\mathrm{ml}$ of sample. Each experiment was performed in triplicate [13].

\section{- Cultivability analysis}

Ten milliliters of each cellular suspension were dispensed into each well of six-well tissue culture plates (Orange Scientific, Braine-l'Alleud, Belgium). Simulating natural conditions, the tissue culture plates were then placed in the dark inside an incubator (Shell Lab, OR, USA) under aerobiosis conditions for $168 \mathrm{~h}$ at $21^{\circ} \mathrm{C}$ 
(room temperature). Next, $10 \mu \mathrm{l}$ samples were taken to assess cultivability, by plating the appropriate dilutions (1:10 dilutions in sterile water) onto CBA in triplicate at the following time points: $0,2,4,6,24,48,96$ and $168 \mathrm{~h}$. Plates were incubated at $37^{\circ} \mathrm{C}$ for 3 to 7 days (depending on the species) under the same microaerophilic conditions used for culture maintenance. After growth, the number of colony forming units (CFUs) were counted. Each individual experiment was carried out threetimes. The area under the curve for each separate experiment was calculated by the trapezium rule [13].

\section{- Adaptation to water}

Cellular suspensions $(10 \mathrm{ml})$ of each strain were dispensed into each well of six-well tissue culture plates (Orange Scientific). The culture plates were incubated (Shell Lab) in the dark under aerobic conditions for $12 \mathrm{~h}$ at $21^{\circ} \mathrm{C}$. After the incubation, the bacteria were plated in CBA and plates were incubated at $37^{\circ} \mathrm{C}$ for 3 to 7 days as described above. After growth, colonies were harvested again and new bacteria suspensions were prepared to be exposed again to water for $12 \mathrm{~h}$. This operation was repeated 20-times for each strain used. After the 20 exposures to water, bacteria exposed for 5 (5E) and 20-times (20E) were compared with those which were with those exposed for the first time (1E) in a $168 \mathrm{~h}$ - cultivability experiment. The $168 \mathrm{~h}$ - cultivability experiment for $5 \mathrm{E}$ and 20E was also performed three-times as described above in the 'cultivability analysis' section.

\section{- Scanning electron microscopy}

Scanning electron microscopy (SEM) analysis was performed for the starting (1E) and final (20E) adaptation periods to increase the chances of finding significant morphological changes. After the exposure for $168 \mathrm{~h}$ to water, a sample of $1 \mathrm{ml}$ of each strain exposed to water was filtered through a 25 -mm black nuclepore polycarbonate membrane with a pore size of $0.2 \mu \mathrm{m}$ (Whatman). The samples were dehydrated using increasing concentrations of ethanol $(10,25,40$, 60, 80, 90 and $100 \%[\mathrm{v} / \mathrm{v}]$ ), during $15 \mathrm{~min}$ for each solution, and then samples were stored in a desiccator. To increase their conductivity, the samples were mounted on aluminium stubs with carbon tape and sputtered with gold. Afterward, samples were observed in a Leica Cambridge S-360 scanning electron microscope (Leo, Cambridge, UK).

\section{- RNA extraction}

After a 12-h cycle of exposure to water (1E, 5E and 20E), the bacterial suspension of $H$. pylori 26695 was transferred to Falcon tube and centrifuged at $7000 \mathrm{rpm}$ for $20 \mathrm{~min}$ at $21^{\circ} \mathrm{C}$. The pellet was resuspended in $1 \mathrm{ml}$ of sterile water and RNA extraction was carried out using PureLink $^{\mathrm{TM}}$ RNA Mini Kit (Invitrogen, CA, USA) according to the manufacturer's instructions, with minor modification. The homogenization and bacterial lysis was performed on Savant Bio 101 FastPrep FP120 homogenizer (Thermo Scientific, MA, USA), with the addition of glass beads. Samples were homogenized for three cycles of $20 \mathrm{~s}$ at a speed of $4 \mathrm{~m} / \mathrm{s}$, placing the samples on ice between cycles. After performing the remainder of the procedure according to the manufacturer's instructions, the final total RNA fraction was obtained by eluting the RNA in $50 \mu \mathrm{L}$ of RNase-free water (Invitrogen). To digest contaminating DNA, DNase (Invitrogen) treatment was performed by adding $5 \mu \mathrm{l}(10 \times)$ of DNase buffer with $\mathrm{MgCl}_{2}$ and $1 \mu \mathrm{l}$ DNase I to the extracted RNA. The mixture was incubated at room temperature for 15 min. Subsequently, $1 \mu \mathrm{l}$ of $25 \mathrm{mM}$ EDTA was added and incubated at $65^{\circ} \mathrm{C}$ for $10 \mathrm{~min}$ to inactivate the DNase I. The concentration and purity of the total RNA was spectrometrically assessed using a NanoDrop $1000^{\mathrm{TM}}$ (Thermo Scientific, MA, USA). The integrity of the total RNA was assessed by electrophoresis through visualization of the $23 \mathrm{~S} / 16 \mathrm{~S}$ banding pattern. Electrophoresis was carried out at $110 \mathrm{~V}$ for $45 \mathrm{~min}$ using a $1 \%$ agarose gel (Bio-Rad Laboratories, Amadora, Portugal). The gel was stained with GelRed (Biotium, CA, USA) and visualized using a GelDoc2000 (Bio-Rad). Total RNA extractions were performed three-times using different cell suspensions.

\section{- Real-time PCR}

Ten microliters of the total RNA suspension were reverse transcribed using an iScript ${ }^{\mathrm{TM}}$ cDNA Synthesis Kit (Bio-Rad) following the manufacturer's instructions. Primers for real-time PCR (qPCR; Table 1) were designed using the PRIMER3 web-based software [26]. Primers efficiency was determined by the dilution method and temperature gradient reaction from 49 to $57^{\circ} \mathrm{C}[27,28]$.

The experiment was performed using the CFX96 TM thermocycler (Bio-Rad) and Sso Fast $^{\mathrm{TM}}$ Evagreen Supermix $2 \times$ mix (Bio-Rad) 
as dye for the quantification of double-stranded DNA. The following cycling parameters were used: $2 \mathrm{~min}$ at $98^{\circ} \mathrm{C}$ followed by 39 repeats of $10 \mathrm{~s}$ at $98^{\circ} \mathrm{C}, 10 \mathrm{~s}$ at $57^{\circ} \mathrm{C}$ (depending on the annealing temperature of each primer [view Table 1]), and finally $5 \mathrm{~s}$ at $65^{\circ} \mathrm{C}$. During the qPCR experiments, three housekeeping genes - gyrB, glm $M$ and $u r e A$ were used [29-31]. However, only one, ure $A$, remained constant under our experimental conditions and thus was used to normalize the data. To ensure the absence of genomic DNA contamination, a nonreaction template (total RNA) and a negative control (RNase-free water) was included in each qPCR. The melting curves were evaluated to ensure the absence of unspecific products and primer dimer formation. The expression of all genes was determined by using the $\Delta \mathrm{Ct}$ method $\left(2^{\Delta \mathrm{Ct}}\right)$, a variation of the Livak and Schmittgen method [32].

\section{- Statistical treatment}

Statistical analysis was carried out using SPSS software (SPSS, Inc., IL, USA). Cultivability results were statistically analyzed by employing analysis of variance. A level of significance of $p<0.01$ was considered. To analyze the expression of genes, data normality was tested by the application of the Kolmogorov-Smirnov test. For variables with a normal distribution, the independent-samples t-test was applied. For variables without normal distribution, the Mann-Whitney U test was used for independent groups. A level of significance of $\mathrm{p}<0.05$ was considered.

\section{Results}

\section{- Cultivability in water}

The first task of this work involved the adaptation of a set of Helicobacter species to water. While the aim of this study is to investigate $H$. pylori

\begin{tabular}{|c|c|c|c|c|}
\hline Target gene & Gene description & \multicolumn{2}{|c|}{ Primers sequence $\left(5^{\prime}\right.$ to $\left.3^{\prime}\right)$} & $\begin{array}{l}\text { Annealing } \\
\text { temperature }\end{array}$ \\
\hline \multirow[t]{2}{*}{$g y r B^{\dagger}$} & \multirow[t]{2}{*}{ DNA gyrase subunit B } & FW & CGTCGCTTTGGATCATTTTT & \multirow[t]{2}{*}{$55^{\circ} \mathrm{C}$} \\
\hline & & RV & AATGGCGTGCCACTTTTAAC & \\
\hline \multirow{2}{*}{$g \operatorname{lm} M^{+}$} & \multirow[t]{2}{*}{ Phosphoglucosamine mutase } & FW & CAACCGCTTGAGAAGAAAGG & \multirow[t]{2}{*}{$54^{\circ} \mathrm{C}$} \\
\hline & & RV & CCAACCAATTAAGCCAGGAA & \\
\hline \multirow[t]{2}{*}{ ure $^{\dagger}$} & \multirow[t]{2}{*}{ Urease subunit alpha } & FW & TTTCACGCTAACGGCTTTTT & \multirow[t]{2}{*}{$54^{\circ} \mathrm{C}$} \\
\hline & & RV & AACCGGATGATGTGATGGAT & \\
\hline \multirow[t]{2}{*}{$\operatorname{csd} 1$} & \multirow[t]{2}{*}{ ToxR-activated protein (tagE) } & FW & TCGCATACACAGGGGTGTTA & \multirow[t]{2}{*}{$54^{\circ} \mathrm{C}$} \\
\hline & & RV & TGCGCCTTATCCCTAATGAC & \\
\hline \multirow[t]{2}{*}{$\operatorname{csd} 2$} & \multirow[t]{2}{*}{ ToxR-activated protein (tagE) } & FW & CCTTTCTTTGGTGGGTTTGA & \multirow[t]{2}{*}{$54^{\circ} \mathrm{C}$} \\
\hline & & RV & GCTCTTTATTGTGGGGCAAA & \\
\hline \multirow[t]{2}{*}{$\mathrm{ccm} A$} & \multirow[t]{2}{*}{ Hypothetical protein } & FW & TGCCCTAAAGGCATGATTTC & \multirow[t]{2}{*}{$56^{\circ} \mathrm{C}$} \\
\hline & & RV & GAAGGGGTGGTGCATTCTAA & \\
\hline \multirow[t]{2}{*}{$\operatorname{csd} 3$} & \multirow[t]{2}{*}{ Hypothetical protein } & FW & CGCTCATTCAAGCCCTTATC & \multirow[t]{2}{*}{$57^{\circ} \mathrm{C}$} \\
\hline & & RV & GCTAAAAGGGGGTCATTGGT & \\
\hline \multirow[t]{2}{*}{$\operatorname{csd} 4$} & \multirow[t]{2}{*}{ Hypothetical protein } & FW & TTAAACCCACCAGGCTCATC & \multirow[t]{2}{*}{$54^{\circ} \mathrm{C}$} \\
\hline & & RV & GGCTTGTGTTCTTGGGTGTT & \\
\hline \multirow[t]{2}{*}{$\operatorname{csd5}$} & \multirow[t]{2}{*}{ Hypothetical protein } & FW & TTCTTCTGTGGCAGTTGTGG & \multirow[t]{2}{*}{$54^{\circ} \mathrm{C}$} \\
\hline & & RV & GGCCTTTGTTGGTGGTTTTA & \\
\hline \multirow[t]{2}{*}{ pbp1 } & \multirow[t]{2}{*}{ Penicillin-binding protein 1A (PBP-1A) } & FW & CAAACTCCCTGTGCCATTTT & \multirow[t]{2}{*}{$55^{\circ} \mathrm{C}$} \\
\hline & & RV & TCAAACCCATGCTCATTGAA & \\
\hline \multirow[t]{2}{*}{ pbp2 } & Penicillin-binding protein 2 (PBP2) & FW & ACGGACTCCCTAATGGCTTT & $54^{\circ} \mathrm{C}$ \\
\hline & & RV & CGTGGGCTTGAGCTTTTTTAG & \\
\hline amiA & $\mathrm{N}$-acetylmuramoyl-L-alanine amidase & FW & ATACGGTTTGCTTTGGATGC & $54^{\circ} \mathrm{C}$ \\
\hline & & RV & GTCCGCAAAAATTACCCTGA & \\
\hline mreC & Rod shaped-determining protein MreC & FW & AACGCTGTGCGTGTCTTCTA & $54^{\circ} \mathrm{C}$ \\
\hline & & RV & GAAAACGCCGATTTGAAAGA & \\
\hline slt & Soluble lytic murein transglycosylase & FW & CTGGGGCTTATGCAAATCAT & $55^{\circ} \mathrm{C}$ \\
\hline & & RV & GGGGGTGGTTGAATTCTTTT" ${ }^{*}$ & \\
\hline
\end{tabular}


adaptation, different Helicobacter species were used to see if there is a specific pattern within the genera. However, since this genera is known to have a viable but nonculturable stage, which is induced under these adverse conditions [6,33], it was necessary to determine the maximum period of exposure to water that would still allow the recovery of all Helicobacter species. To determine this period, an initial experiment was carried out by exposing the different species for $168 \mathrm{~h}$.

To compare the survival times of the different strains in water, inoculums were prepared at the same cell density $\left(10^{8}\right.$ total cells $\left./ \mathrm{ml}\right)$. The data show that the initial level of cultivability is not the same for all species (Figure 1), that is, for some species the percentage of culturable cells was lower. It is also verified that strains have different capacities to maintain their cultivability over time when exposed to water.

Helicobacter canis and $H$. muridarum are the most sensitive species to water (Figure 1), losing their cultivability after $12-24 \mathrm{~h}$ of exposure. All other species were able to remain culturable for more than $24 \mathrm{~h}$. The strains of $H$. pylori remained culturable for at least $48 \mathrm{~h}$. On the other hand, H. bilis and H. salomonis were able to stay culturable until the end of the experience, showing high fitness to this water environment. Based on these data, $12 \mathrm{~h}$ was the maximum time that allowed the recovering of all species by traditional plating technique. As such for adapting the bacteria to water, 20 cycles of $12 \mathrm{~h}$ each were used.

To evaluate how these periods of adaptation to water would affect the cultivability values, after the successive exposures to water, strains with different periods of adaptation, $1 \mathrm{E}, 5 \mathrm{E}$ and $20 \mathrm{E}$, were subjected to the same test of cultivability (168 h). Due to the large number of data obtained, we determined the area under the cultivability curve by the trapezium rule, as described previously [13] (see all the cultivability areas in the Supplementary Table 1).

It is possible to observe that for some Helicobacter spp., including $H$. pylori, $H$. pametensis, H. canis, $H$. pullorum and $H$. bilis, the adaptation to water leads to an increase of the cultivability time. However, this property does not seem to be related with the gastric or enterohepatic nature of the species (Supplementary Table 1). Actually, it is possible to identify two distinct groups: species that have a strong and significant $(\mathrm{p}<0.01)$ increase in their cultivability and strains that do not change considerably their cultivability in water along with the exposure cycles $(H$. canadensis, $H$. cinaedi, $H$. mustelae and $H$. salomonis; Figure 2). It should be noted that $H$. bilis and $H$. salomonis are species that have initially demonstrated high cultivability values in water, which then probably influenced the relative increase in cultivability. The only exception to this general phenomenon was $H$. muridarium, which presented a low initial cultivability, and tends to decrease the cultivability during the adaptation cycles.

Another interesting fact was that the increase in the cultivability occurred mainly in the first cycles of exposure to water (see Supplementary Table $1 \&$ Supplementary Figure 1A \& B). This ability to rapidly adapt was visible for the Helicobacter species that have shown a great ability to increase the cultivability in water, especially for the $H$. pylori strains. The only exception was $H$. pullorum, for which the increase was not noticed at the fifth exposure (Supplementary Figure 1C). For the remaining species, the cultivability property did not change significantly over time (e.g., see Supplementary Figure 1D).

\section{- Changes in cell morphology}

When cultured in vitro under favorable conditions, the majority of $H$. pylori bacteria have a spiral appearance, but exposure to unfavorable conditions typically results in the conversion to a coccoid form [18,34-36]. In this study, H. pylori strains lost their spiral shape after a 168-h exposure period to water (Figure 3A \& B). However, surprisingly, they did not convert into the coccoid form; instead, they seem to favor a rodshaped form. Exposed strains presented minor proportions of spiral bacteria, acquiring more elongated and U-shaped forms (Figure 3A-C). Another important observation is that adapted bacteria (after 20 exposures) present a permanent rod-shape, since bacteria at time 0 do not show the common spiral-shape phenotype (Figure $3 \mathrm{C}$ \& D). Also, for $H$. pylori 26695, the elongation of the cells is visible. For this particular strain, initial spiral shape size was approximately $2.42 \pm 0.14 \mu \mathrm{m}$, while the adapted rod-shape presented approximately $2.96 \pm 0.18 \mu \mathrm{m}$. The same happens with the other $H$. pylori strains in this study. This indicates that adaptation seems to favor the loss of the spiral-shape, but does not necessarily involve the transition to the coccoid usually associated to a dormant state. Nonetheless, these observations are limited to 7 days (168 h). 


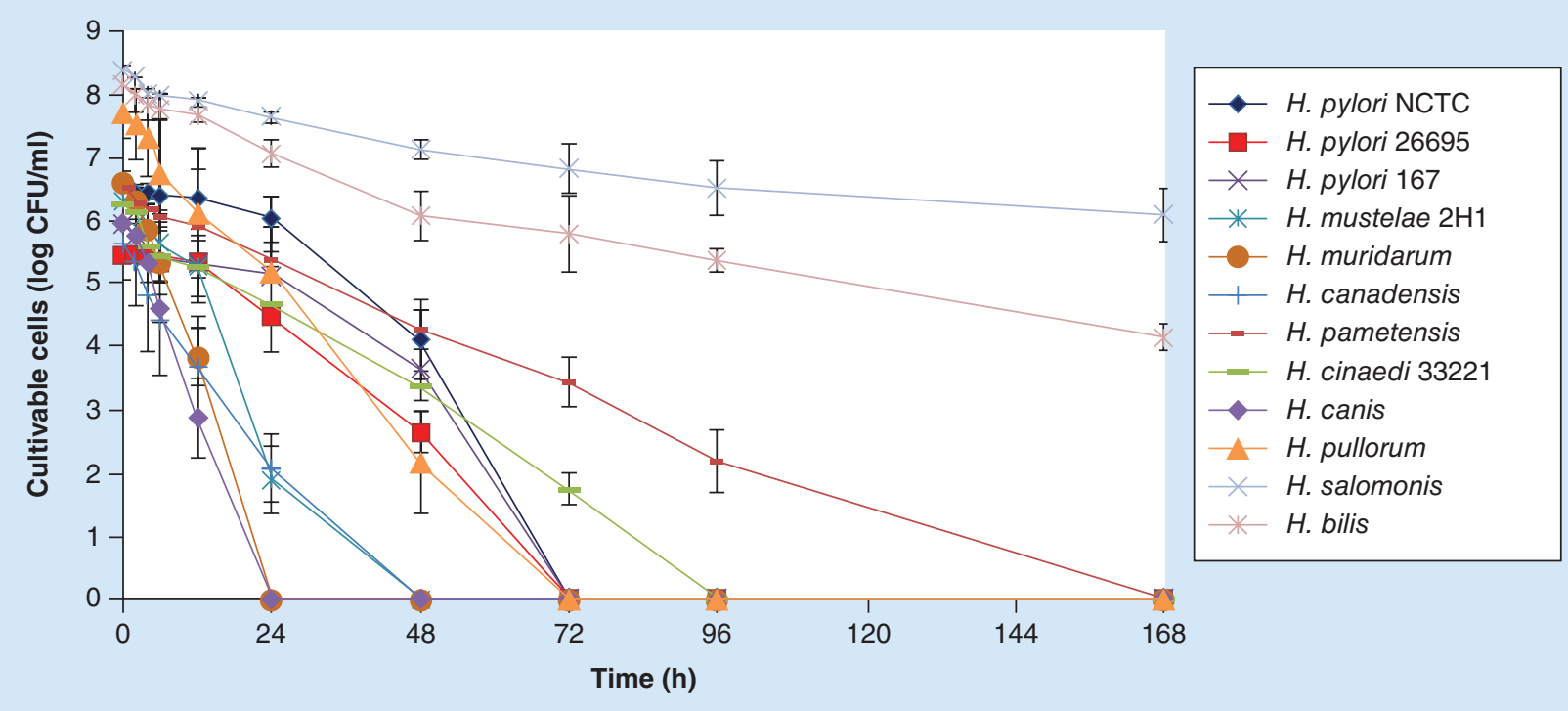

Figure 1. Cultivability of Helicobacter spp. strains in water $\left(21^{\circ} \mathrm{C}\right)$ over $168 \mathrm{~h}$. Each experiment was performed in triplicate and error bars represent the standard deviations.

CFU: Colony forming unit.

The phenomenon of $H$. pylori was not common to all Helicobacter species (Supplementary Table 2). Actually, most of them do not present an initial spiral shape. Nonetheless, it was clear that spirals are more common among nonadapted strains, while for the adapted ones, rods are the dominant form. Elongation was also uncommon, but, interestingly, the species presenting

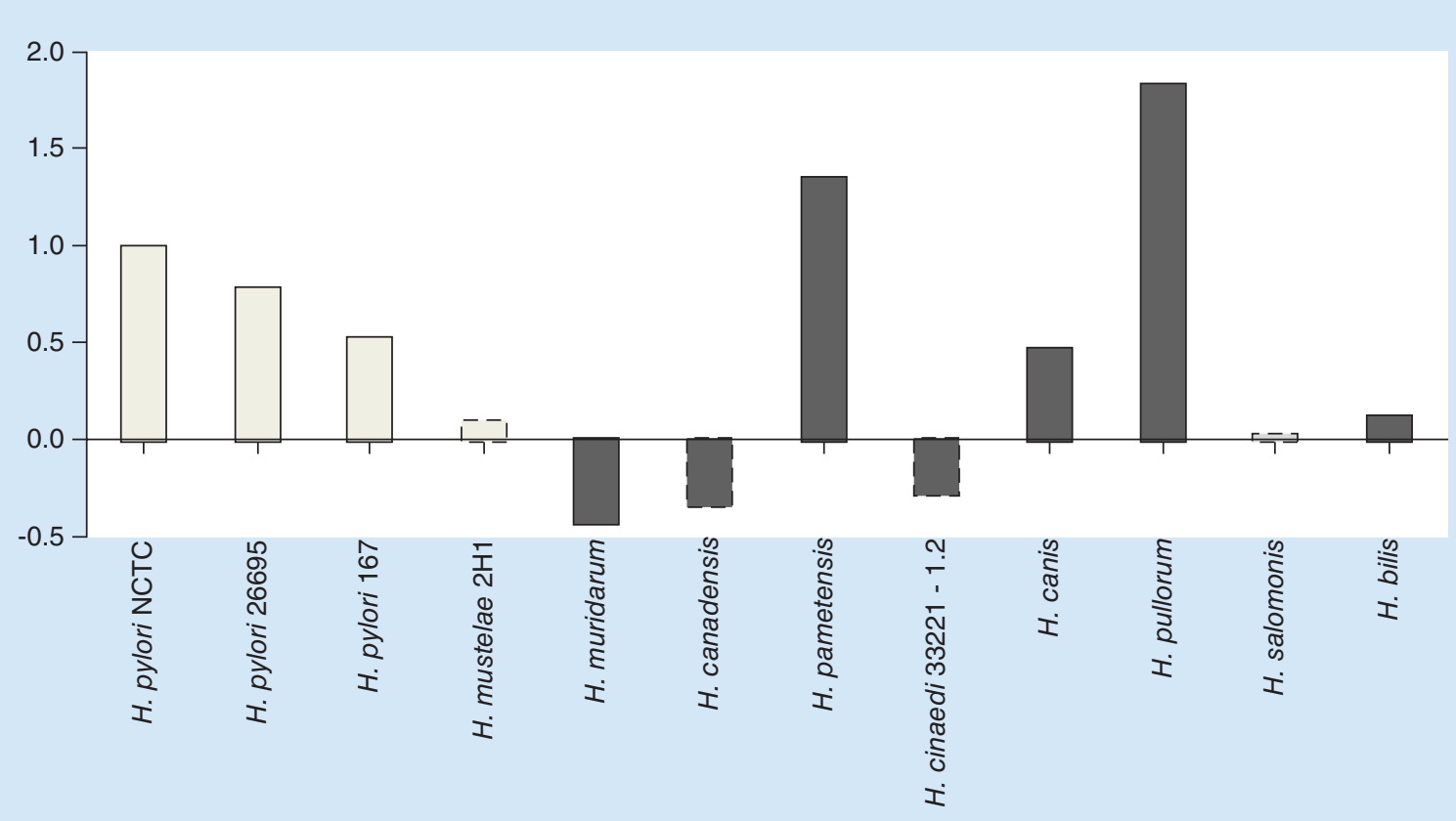

Figure 2. Relative cultivability of the Helicobacter spp. strains adapted to water. Relative values were obtained comparing the cultivability areas of the adapted strains with the cultivability areas of the corresponding nonadapted strains. The white columns represent strains of gastric nature and dark-gray columns represent enterohepatic strains. Columns with dashed lines represent strains with results that are not statistically significant. 
Helicobacter transition during adaption to water RESEARCH ARTICLE
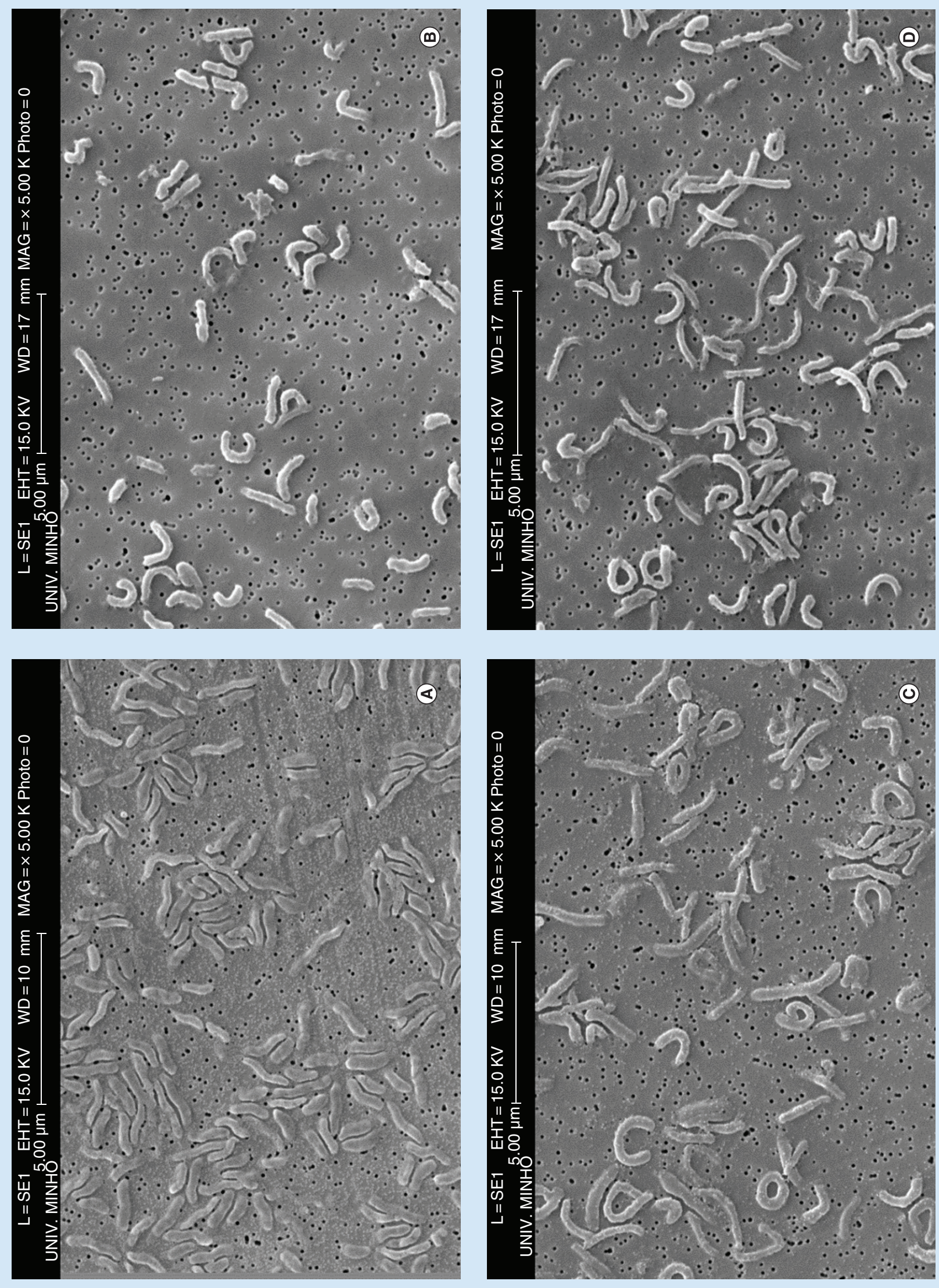
elongation were those with initial spiral forms, which once again might indicate an elusive elongation due to simply the twist loss.

\section{- Genes expression}

The expression of genes involved in the morphological changes in $H$. pylori, were evaluated. Given that $H$. pylori 26695 is a strain with fully sequenced and widely studied genome, the study was restricted to this strain.

Eleven genes, implicated on $H$. pylori peptidoglycan synthesis and renewal [20-25], were evaluated by qPCR (Table 1 \& Figure 4). Strains exposed to $0(0 \mathrm{E}), 1(1 \mathrm{E})$ and 20 (20E) adaptation cycles were studied. Then, the results obtained for adapted strains (1E and 20E) were compared with the nonadapted strain (0E) (Figure 4). Initially, three housekeeping genes: gyrB, glm $M$ and UreA were selected based on previous works [23-25]. However, for the conditions under study, only ure $A$ remained constant. As such, all means of threshold cycle (CT) obtained for each gene were normalized by using ure $A \mathrm{Ct}$ values for each condition.

Considering fold change $\geq 2$ as threshold of increase or decrease [37], no significant changes in the genes expression were observed for strains subjected to one exposure cycle (1E). However a wide variation in the expression of all the genes implicated in the peptidoglycan synthesis for strains exposed to 20 adaptation cycles is clear (Figure $4-20 \mathrm{E}$ ). The only exception was $\mathrm{ccm} A$ gene, for which no statistically significant results were observed $(\mathrm{p}<0.05)$.

\section{Discussion}

Since culture method can be used to reliably estimate differences in survival among different Helicobacter spp. [13], we have adapted different Helicobacter species to water and assessed their cultivability after adaptation. This work is pioneer in the attempt to adapt and study adaptation mechanisms of different Helicobacter species to water.

Bacteria were adapted by exposing them sequentially to water for 20 cycles. This is not a very high number of cycles, but the fastidious nature of this bacterium makes this task extremely time consuming, taking several months to complete.

Bacteria were grown under microaerophilic conditions and then exposed to water at $21^{\circ} \mathrm{C}$ and standard atmosphere. After each exposure, water samples were plated and let to grow under microaerophilic conditions. In fact, recovery of all species after each cycle of adaptation to water under standard atmosphere and low nutrient environments, is slower than when species are maintained under microaerophilic conditions [15] and, in fact, this effect might change between species/strains (as it can be seen at Supplementary Figure 1). However, for the estimation of the cultivability changes over adaptation, the recovery values were obtained by comparison with the initial recovery values observed in water for each particular strain. As such, this estimation takes into account this possible effect.

Results demonstrated that some Helicobacter species (H. pylori, H. pametensis, H. canis,

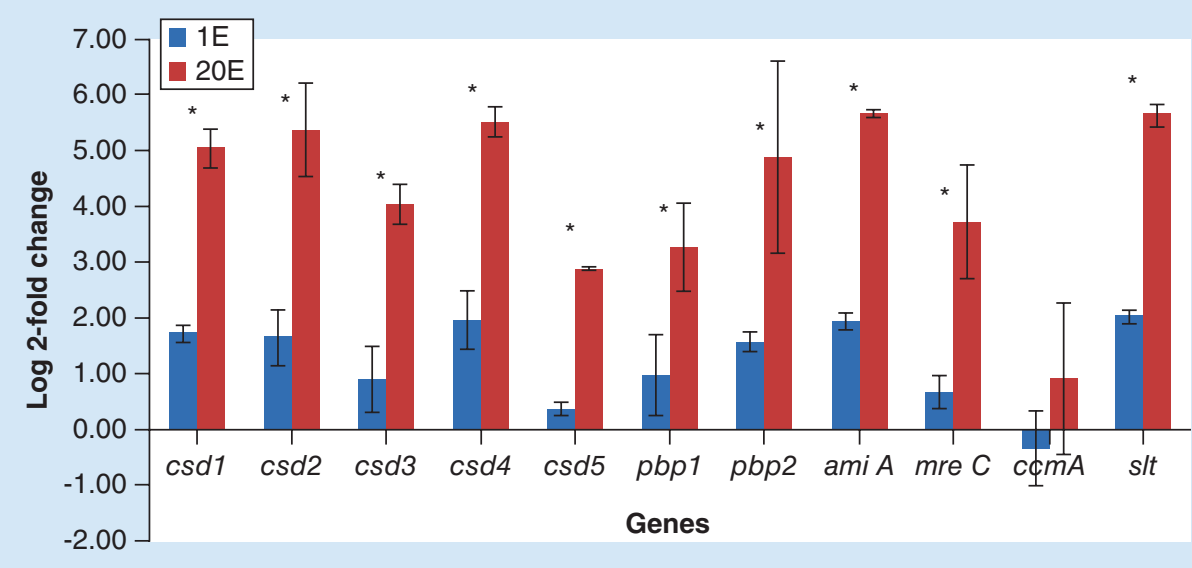

Figure 4. Expression of the genes involved in the peptidoglycan synthesis for Helicobacter pylori 26695 strains exposed 1-time (1E) and 20-times (20E) to water. The control condition used was H. pylori 26695 nonexposed to water (two days growth in CBA).

* Results statistically significant $(p<0.05)$. 
H. pullorum and H. bilis) increased their survival in water with the number of exposure cycles, demonstrating an ability to adapt to water. For instance, $H$. pylori, that lost cultivability between 48 and $72 \mathrm{~h}$, after adaptation will lose cultivability later, between 72 and $96 \mathrm{~h}$. However, the adaptation is not transversal to all Helicobacter spp. There are some species that did not increase cultivability in water even at the end of the adaptation process. This property was independent of the nature gastric or enterohepatic of the bacterium and the host organism. These results are in agreement with those obtained by Azevedo et al. (2008) [13]. Results also indicate that $H$. pylori adaptation happens very fast, since bacterium survival in water increases drastically in the first five exposures.

\section{- Morphological changes during adaptation}

Several authors report that $H$. pylori undergoes a morphological change from spiral to coccoid and U-shaped forms in water, which probably contributes to the loss of culturability $[6,19]$. Considering the frequent association of coccoid form to detrimental conditions, we would expect to find high percentages of cells into this shape [6,19]. However, in here, the evaluation of the cell morphology for the adapted strains has shown that transition to coccoid form might not be involved in cell adaptation to water. Actually, adaptation seems to correlate well with the rod shape and elongation and, consequently, increased cultivability. This was a surprising observation, since it has been suggested that $H$. pylori strains exposed to non-optimum conditions tend to accelerate the transition to the coccoid form [12,19,34]. In our case, it seems that adaptation mechanism might involve the passage from spiral to bacillary forms, including a U-shaped bacteria, a possible intermediate state in this process. Cellular processes that lead to the loss of $H$. pylori spiral shape in adverse conditions, or the advantages of this morphological change, are not yet clear. Spiral shape has been associated with the ability to move in viscous medium, such as the gastric mucus [21]. This means that helical shape might be needless in water environments and can also imply unnecessary energetic cost for the bacterium. Also, the loss of the spiral results in an apparent cellular elongation (Supplementary Table 2) that might increase the cellular uptake-proficiency by increasing the surface-to-volume ratio appreciably [38]. Actually, this phenomenon has been previously described for other bacteria exposed to low-nutrient conditions $[12,15,39]$. These features were not transversal to all Helicobacter species (Supplementary Table 2); but, in fact, the prevalence of rod-shaped cells for all species/strains adapted to water was observed.

\section{- Genes involved in the permanent loss of spiral shape}

Several studies have shown through directed mutagenesis that $H$. pylori morphological changes are mainly dependent on the genes involved in the peptidoglycan synthesis [20-25]. The involvement of some genes in peptidoglycan structure change, and consequently the morphological change, has been demonstrated through directed mutagenesis; but the mechanism by which the loss of spiral shape occurs remains elusive so far [22-25]. The evaluation of cell morphology has suggested a relation between the adaptation to water in $H$. pylori strains and the permanent loss of the spiral shape. In this study, we have selected 11 genes described as required for the morphological changes in this bacterium.

Sycuro et al. identified four genes involved in the helical shape of $H$. pylori: csd1, csd2, cds 3 and ccmA [24]. Later, these authors concluded that the $c s d$ proteins were involved in the hydrolysis of the cross-link $m$ Dap-D-Ala, presenting functions of DD-endopeptidase. Furthermore, it is believed that csd3 present a double function of carboxypeptidase and endopeptidase (Figure 5A). Regarding the $\operatorname{ccm} A$, there is no homologous sequence described, but it seems to be involved in the hydrolysis of tetra-penta-peptide [24]. However, our results indicate that $\mathrm{ccm} A$ is not involved in the process described here. In this work, the high expression levels observed for $c s d 1$, $c s d 2$ and $c s d 3$ genes suggest that the corresponding hydrolytic enzymes (endopeptidases and carboxypeptidases) promote the relaxation of peptidoglycan in twist zone by decreasing the peptidoglycan cross-links resulting in the loss of spiral shape.

In addition to the genes involved in the cleavage of peptidoglycan cross-links, there are other genes, $c s d 4, c s d 5$, slt and amiA, also suspected of being involved in the peptidoglycan lysis [21-23]. csd4 and $c s d 5$ genes encode for a DL-carboxypeptidase and a putative scaffolding protein, respectively. amiA gene encodes a peptidoglycan amidase, which cleaves the peptidoglycan between the $\mathrm{N}$-acetylmuramic acid residue and the first amino acid residue of the peptide 
RESEARCH ARTICLE Fernandes, Silva, Oliveira, Almeida, Azevedo \& Vieira

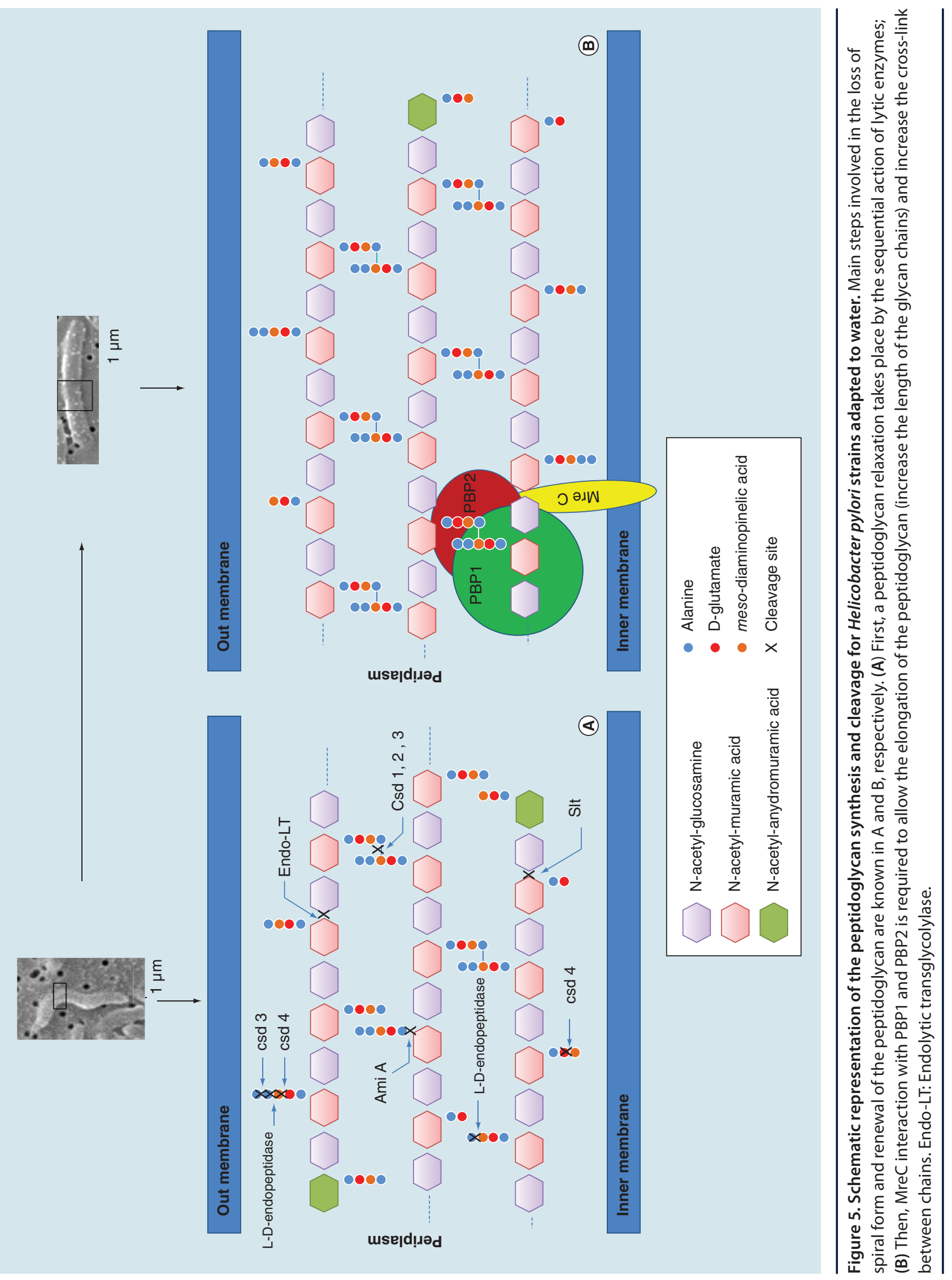


moiety, L-alanine [20]. It is thought that amiA gene is bifunctional, encoding also a protein with consistent carboxy/endopeptidase activity capable of recognizing $\gamma$-D-glutamyl-meso-diaminopimelic acid bond [22]

In addition to the amidase activity, we also have lytic transglycosylases enzymes involved in this process. Only slt gene, which encodes exolytic transglycosylases that recognize N-acetylglucosamine-N-acetylmuramic acid-tripeptide, was evaluated here [23]. Since the Slt only recognizes the terminal monomer N-acetylglucosamine-N-acetylmuramic-tripeptide, we suggest that other endolytic transglycosylases may exist in order to recognize monomers of glycan attached to different types of peptides (resulting of action of Csd4 and AmiA [Figure 5]). An endolytic transglycosylases, MltD, is described for $H$. pylori. Authors suggested that Slt is mainly involved in peptidoglycan turnover and MltD is involved in the rearrangement of the peptidoglycan. Both genes may be important in modifying the structure of peptidoglycan and hence causing the morphological change of the bacterium.

Taking all this information together, and the overexpression observed for these genes (amiA, $c s d 4, c s d 5$ and $s l t$ ), results suggest that, in association to the decreasing peptidoglycan cross-links mentioned above, we also have the cleavage of the peptides $C^{\prime}$-terminal and cleavage of the old glycan strands (Figure 5).

It is thought that the action of Csd3 as carboxypeptidase may be the enhancer of pentapeptide degradation, since initial cleavage will allow the successive action of a still unknown LD-carboxypeptidase and Csd4. The result of the successive action of these enzymes will lead to the formation of tetra-, tri- and dipeptides, respectively. Since $c s d 5$ gene (encodes a putative scaffolding protein, which normally act in certain signaling pathways) exact function is unknown, and despite its clear overexpression, it was not represented in the model.

This coordinated process allows the cleavage of old monomers and insertion of new, leading later to the increase of the glycan chains length and the crosslink, through the joint action of PBP1, PBP2 and membrane proteins (MreC) [24,25,40] (Figure 5B).

Given the overexpression of all genes analyzed (except $\operatorname{ccm} A$ ) in strain 20E, and based on the studies referenced above, a model was generated where the rearrangement of peptidoglycan structure of this bacterium and consequent loss of spiral shape, is evidenced. First, there is the cleavage of peptide cross-links by Csd1, Csd 2 and Csd3. Then, the intrapeptide bonds are also cleaved by sequential action of Csd3, an unknown DL-carboxypeptidase and Csd4, that allow an initial relaxation of peptidoglycan in the twist zone, losing helical form. Following, monomers that have been subjected to the enzymatic action, are recognized for different lytic transglycosylases, as Slt and MltD, being removed for the subsequent insertion of new monomers. Finally, the insertion of new monomers in the peptidoglycan and, consequent elongation, is performed by PBP1, PBP2 and membrane proteins (MreC). This thereby increases the length of the glycan chains and cross-link.

\section{Conclusion}

In general, the adaption of some Helicobacter spp., and particularly $H$. pylori, seems to involve a metabolic change, which favors the culturable phenotype, and a morphological transition. Instead of a coccoid shape associated to detrimental conditions, the bacterial might acquire a permanent elongated rod shape. In this process, enzymes associated to the peptidoglycan turnover are implicated. The overexpression verified for six genes involved in the peptidoglycan lysis, allowed an initial relaxation of peptidoglycan in the twist zone, resulting in the loss of the helical form. Subsequently, by coordinated action of the PBP, it was possible to increase the length of the chains and cross-link, giving rise to the rod shape. Considering the expression levels for $H$. pylori adapted for 1 or 20 cycles, adaptation seems to involve the acceleration and, later, the maintenance of this cycle of peptidoglycan renewal.

\section{Acknowledgements}

C Almeida also thanks FCT for the postdoctoral fellowship SFRH/BPD/74480/2010.

Financial \& competing interests disclosure

This work was supported by the Portuguese Foundation for Science and Technology (FCT) under the project 'Heliwater' (PTDC/BIA-MIC/108811/2008), the strategic funding of UID/BIO/04469/2013 unit and COMPETE 2020 (POCI-01-0145-FEDER-006684) and BioTecNorte operation (NORTE-01-0145-FEDER-000004) funded by the European Regional Development Fund under the scope of Norte2020 - Programa Operacional Regional do Norte.

No writing assistance was utilized in the production of this manuscript. 


\section{Ethical conduct of research}

The authors state that they have obtained appropriate institutional review board approval or have followed the principles outlined in the Declaration of Helsinki for all human or animal experimental investigations. In addition, for investigations involving human subjects, informed consent has been obtained from the participants involved.

\section{Supplementary data}

To view the supplementary data that accompany this paper please visit the journal website at: www. futuremedicine.com/doi/full/10.2217/ fmb-2016-0174.

\section{EXECUTIVE SUMMARY}

- Recent studies have provided evidence for waterborne transmission of Helicobacter pylori.

- Morphological transition seems to be involved in the survival of $H$. pylori in water.

- H. pylori presents increased cultivability in water after adaptation.

- Adaptation favors the rod-shape instead of the spiral- or coccoid-shape.

- Genes involved in peptidoglycan turnover are involved in the transition process to the rod-shape.

- The same transition to rod-shape is observed in other Helicobacter species.

- Water adaptation favors the culturable phenotype.

\section{References}

Papers of special note have been highlighted as:

- of interest; $\bullet$ of considerable interest

1 Brown LM. Helicobacter pylori: epidemiology and routes of transmission. Epidemiol. Rev. 22(2), 283-297 (2000).

2 Khalifa MM, Sharaf RR, Aziz RK. Helicobacter pylori: a poor man's gut pathogen? Gut Pathog. 2(1), 2 (2010).

3 Giao MS, Azevedo NF, Wilks SA, Vieira MJ, Keevil CW. Persistence of Helicobacter pylori in heterotrophic drinking-water biofilms. Appl. Environ. Microbiol. 74(19), 5898-5904 (2008).

4 Fujimura S, Kato S, Watanabe A. Water source as a Helicobacter pylori transmission route: a 3-year follow-up study of Japanese children living in a unique district. J. Med. Microbiol. 57(Pt 7), 909-910 (2008).

5 Hulten K, Han SW, Enroth H et al. Helicobacter pylori in the drinking water in Peru. Gastroenterology 110(4), 1031-1035 (1996).

6 Bellack NR, Koehoorn MW, Macnab YC, Morshed MG. A conceptual model of water's role as a reservoir in Helicobacter pylori transmission: a review of the evidence. Epidemiol. Infect. 134(3), 439-449 (2006).

- A review on the evidence of Helicobacter pylori waterborne transmission.

7 Hestvik E, Tylleskar T, KadduMulindwa DH et al. Helicobacter pylori in apparently healthy children aged $0-12$ years in urban Kampala, Uganda: a communitybased cross sectional survey. $B M C$ Gastroenterol. 10, 62 (2010).
8 Al-Sulami AA, Al-Taee AM, Juma’a MG. Isolation and identification of Helicobacter pylori from drinking water in Basra governorate, Iraq. East Mediterr. Health J. 16(9), 920-925 (2010).

9 Lu Y, Redlinger TE, Avitia R, Galindo A, Goodman K. Isolation and genotyping of Helicobacter pylori from untreated municipal wastewater. Appl. Environ. Microbiol. 68(3), 1436-1439 (2002).

- An example of an article describing the presence of clinical relevant $H$. pylori strains in municipal wastewater systems.

10 Nayak AK, Rose JB. Detection of Helicobacter pylori in sewage and water using a new quantitative PCR method with SYBR green. J. Appl. Microbiol. 103(5), 1931-1941 (2007).

11 Moreno Y, Ferrus MA, Alonso JL, Jimenez A, Hernandez J. Use of fluorescent in situ hybridization to evidence the presence of Helicobacter pylori in water. Water Res. 37(9), 2251-2256 (2003).

12 Adams BL, Bates TC, Oliver JD. Survival of Helicobacter pylori in a natural freshwater environment. Appl. Environ.

Microbiol. 69(12), 7462-7466 (2003).

13 Azevedo NF, Almeida C, Fernandes I et al. Survival of gastric and enterohepatic Helicobacter spp. in water: implications for transmission. Appl. Environ. Microbiol. 74(6), 1805-1811 (2008).

- Evaluates the Helicobacter species survival in water.

14 Azevedo NF, Vieira MJ, Keevil CW. Development of an optimized technique for the recovery of $H$. pylori from water and drinking water biofilms. In: Biofilms: persistence and ubiquity Biofilm Club, Manchester, UK, 221-229 (2005).

15 Azevedo NF, Pacheco AP, Keevil CW, Vieira MJ. Nutrient shock and incubation atmosphere influence recovery of culturable Helicobacter pylori from water. Appl. Environ. Microbiol. 70 (1), 490-493 (2004).

16 Sorberg M, Nilsson M, Hanberger H, Nilsson LE. Morphologic conversion of Helicobacter pylori from bacillary to coccoid form. Eur. J. Clin. Microbiol. Infect. Dis. 15(3), 216-219 (1996).

17 Shi X, Rao NN, Kornberg A. Inorganic polyphosphate in Bacillus cereus: motility, biofilm formation, and sporulation. Proc. Natl Acad. Sci. USA 101(49), 17061-17065 (2004).

18 Andersen LP, Wadstrom T. Basic bacteriology and culture. In: Helicobacter pylori: Physiology and Genetics. Mobley HLT, Mendz GL, Hazell SL (Eds). ASM Press, DC, USA (2001).

19 Azevedo NF, Almeida C, Cerqueira L, Dias S, Keevil CW, Vieira MJ. Coccoid form of Helicobacter pylori as a morphological manifestation of cell adaptation to the environment. Appl. Environ. Microbiol. 73(10), 3423-3427 (2007).

20 Boneca IG. The role of peptidoglycan in pathogenesis. Curr. Opin. Microbiol. 8(1), 46-53 (2005).

21 Sycuro LK, Wyckoff TJ, Biboy J et al. Multiple peptidoglycan modification networks modulate Helicobacter pylori's cell 
shape, motility, and colonization potential. PLoS Pathog. 8(3), e1002603 (2012).

- An article that investigates the peptidoglycan role of $H$. pylori phenotype.

Chaput C, Ecobichon C, Cayet N et al. Role of AmiA in the morphological transition of Helicobacter pylori and in immune escape. PLoS Pathog. 2(9), e97 (2006).

23 Chaput C, Labigne A, Boneca IG. Characterization of Helicobacter pylori lytic transglycosylases Slt and MltD. J. Bacteriol. 189(2), 422-429 (2007).

24 Sycuro LK, Pincus Z, Gutierrez KD et al. Peptidoglycan crosslinking relaxation promotes Helicobacter pylori's helical shape and stomach colonization. Cell 141(5), 822-833 (2010).

-• An article that describes four genes involved on peptidoglycan synthesis and their effect on $H$. pylori gastric colonization.

25 El Ghachi M, Mattei PJ, Ecobichon C et al. Characterization of the elongasome core PBP2: MreC complex of Helicobacter pylori. Mol. Microbiol. 82(1), 68-86 (2011).

26 Primer3. http://frodo.wi.mit.edu/primer3

27 Silva S, Hooper SJ, Henriques M, Oliveira R, Azeredo J, Williams DW. The role of secreted aspartyl proteinases in Candida tropicalis invasion and damage of oral mucosa. Clin. Microbiol. Infect. 17(2), 264-272 (2011).
28 Franca A, Melo LD, Cerca N. Comparison of RNA extraction methods from biofilm samples of Staphylococcus epidermidis. BMC Res. Notes 4, 572 (2011).

29 Liu ZQ, Zheng PY, Yang PC. Efflux pump gene hefA of Helicobacter pylori plays an important role in multidrug resistance. World J. Gastroenterol. 14(33), 5217-5222 (2008).

30 Espinoza MG, Vazquez RG, Mendez IM, Vargas CR, Cerezo SG. Detection of the glmM gene in Helicobacter pylori isolates with a novel primer by PCR. J. Clin. Microbiol. 49(4), 1650-1652 (2011).

31 Kim N, Marcus EA, Wen Y et al. Genes of Helicobacter pylori regulated by attachment to AGS cells. Infect. Immun. 72(4), 2358-2368 (2004).

32 Livak KJ, Schmittgen TD. Analysis of relative gene expression data using real-time quantitative PCR and the 2(-Delta Delta C(T)) Method. Methods 25(4), 402-408 (2001).

33 Nilsson HO, Blom J, Abu-Al-Soud W, Ljungh AA, Andersen LP, Wadstrom T. Effect of cold starvation, acid stress, and nutrients on metabolic activity of Helicobacter pylori. Appl. Environ. Microbiol. 68(1), 11-19 (2002).

34 Kusters JG, Gerrits MM, Van Strijp JA, Vandenbroucke-Grauls CM. Coccoid forms of Helicobacter pylori are the morphologic manifestation of cell death. Infect. Immun. 65(9), 3672-3679 (1997).
35 Narikawa S, Kawai S, Aoshima H et al. Comparison of the nucleic acids of helical and coccoid forms of Helicobacter pylori. Clin. Diagn. Lab Immunol. 4(3), 285-290 (1997).

36 Benaissa M, Babin P, Quellard N, Pezennec L, Cenatiempo Y, Fauchere JL. Changes in Helicobacter pylori ultrastructure and antigens during conversion from the bacillary to the coccoid form. Infect. Immun. 64(6), 2331-2335 (1996).

37 Himpsl SD, Pearson MM, Arewang CJ, Nusca TD, Sherman DH, Mobley HL. Proteobactin and a yersiniabactin-related siderophore mediate iron acquisition in Proteus mirabilis. Mol. Microbiol. 78(1), 138-157 (2010).

38 Young KD. The selective value of bacterial shape. Microbiol. Mol. Biol. Rev. 70(3), 660-703 (2006).

-• A review that tries to elucidate the role of bacterial shape on their survival and adaptation to environmental conditions.

39 Steinberger RE, Allen AR, Hansa HG, Holden PA. Elongation correlates with nutrient deprivation in Pseudomonas aeruginosa-unsaturates biofilms. Microb. Ecol. 43(4), 416-423 (2002).

40 Typas A, Banzhaf M, Gross CA, Vollmer W. From the regulation of peptidoglycan synthesis to bacterial growth and morphology. Nat. Rev. Microbiol. 10(2), 123-136 (2012). 